\title{
6 What was Published is as Important as How it was Published
}

\subsection{Introduction}

Archaeology is a complex discipline which studies the past based on material evidence. There are three main fields of research archaeology: prehistoric, historic and contemporary. Beyond research archaeology, which includes field excavations, systematisation and interpretation of data, there is also theoretical archaeology; other classifications may also include academic archaeology and public archaeology. All fields and subdisciplines cross over each other, and it is therefore, useful to think about archaeology as a complex discipline of the material past (Nikolova, 2013).

It is essential to understand that archaeology is a sensitive social discipline since people have different approaches to the past, and the social, political and cultural context of archaeology in different countries is vastly diverse. Archaeologists have social twins - treasure-hunters - while government museums compete with private museums and collectors. These two realities, although in many cases analysed separately, complicate the function of archaeology as a subculture in the contemporary global world.

The global value of open access (OA), which is recognised by support at the highest levels of government (Lenzer, 2008), turns the goals of the author of this chapter toward searching for perspectives of increasing of the role of open access in archaeology as a discipline which produces and depends on enormous amounts of reports and publications.

\subsection{Open Access and Global Society}

$\mathrm{OA}$ in $21^{\text {st }}$ century science refers to providing unrestricted online access to scholarly material, such as journal articles, theses, monographs, book chapters and other online materials. OA innovation in the scholarly world is a consequence of the development of the internet and globalisation (Suber, 2012). As a theoretical category, OA speeds the advance of the science through the dissemination of information about the newest discoveries. Another argument to widening the access of scholarly publications, is that the taxpaying public deserves access to the outputs of the research they

Lolita Nikolova: International Institute of Anthropology, Utah, USA 
fund (Neylon, 2013, p. 1). Re-use - beyond the initial reading and financial platform - may include re-analysis and re-distribution of archaeological reports and data (see also Beck and Neylon 2012).

In the early $21^{\text {st }}$ century, OA databases have had the same revolutionary role in human society as, for instance, the Bauhaus Period (1919-1923) advances of architecture and design. The internet itself is a sort of tool that can be used in a variety of ways. The internet includes elements of high culture, communication innovation, spam, danger, crime, etc. How science uses the internet is crucial for the future of culture, since science is the father of culture, in the way that art is its mother.

$\mathrm{OA}$ is misleading from the perspectives of the publishers of scientific papers, since $\mathrm{OA}$, in most cases, means that the publishers should be paid by the institutions or by the authors. Even if an author would like to publish in a popular OA journal, it may be impossible because of publishing fees. OA can be seen as a coin with different values - while authors volunteer or pay, publishers have benefit from the profit of the publications. McCabe et al. (2013) created an economic model - based on the platform market theory - to attempt to clarify in which cases the publishers would prefer open access.

Beyond the traditional classification ("green" and "gold" open access, and gratis and libre) (Open access, online), we can offer the following classification:

1. Completely OA journals

2. Journals with OA selected articles of whole issues.

3. Websites with links or .pdf files of OA publications.

4. Books with "look inside" (books.google.com, amazon.com).

5. Academic profiles at academia.edu

6. OA librarian metadata

7. OA Museum database

8. OA virtual museums

9. OA data base of excavations

10. Reports of excavations published online (e.g. Catahüyük's reports of the team directed by Ian Hodder).

11. Abstracts published online.

12. Complimented materials to hard-copies published online as OA.

13. Blogs with texts which have values of scientific publications because of originality.

14. Open access videos (e.g. youtube.com, Vimeo.com), etc.

15. Open access through academic hosts (for students and instructors/professors) (e.g. EBSCO e-books and EBSCO articles), etc.

Key meetings and initiatives which stimulated the OA publications include the $\mathrm{Bu}$ dapest Open Access Initiative (BOAI) in 2002 and Global Open Access weeks. The European Union plans for up to $100 \%$ of funded Horizon Research Programs to be OA by 2020 (Macilwain, 2013, p. 7). PubMed Central, which is operated by the Na- 
tional Center for Biotechnology Information (NCBI), a division of the National Library of Medicine (NLM) at the U.S. National Institutes of Health (NIH) has a very active positive role within the USA (Kurata et al., 2013). Leading universities (Harvard, Massachusetts, Stanford, Kansas) have passed an OA policy granting a license to share their scholarly journal articles openly (Emmett et al., 2011). According to some authors, by 2010 about $20 \%$ of the scientific research was available as OA (Björk et al., 2010). However, for some areas of the field - such as Africa Open Access - there is limited support by local governments and OA has a fragmented status (Nwagwu, 2013). Personally, the author has been experiencing the positivity of Open Publishing (OP) through the popularity at Academia.edu of her first OA published article (Nwagwu, 2013). In the context of global interest in OA, archaeologists have been expanding their contributions by increasing the number of open publications (OA archaeology online), discussing the theory of the subject (e.g. Lake 2012), and creating OA communities (Open Access Archaeology on Facebook).

The motifs outlined below in this chapter include an artistic reflection on OA in archaeology and open science.

"O like Open” (Fig 6.1a) expresses the limitation of open - it requires direction and usually the success depends on narrowing of paradigms. There is an interconnection between openness in science and ethics. Ethics is a framework and its application means limitation. The difference between open and moral is that open is the right to freely communicate scholarly mind, while moral is mostly about what one should not do. People who oppose OA from moral perspectives (e.g. authorship) in fact belong to those segments of society which always look at human culture as a sum of often not interacting and not related subculture. The supporters of open success look at society as a whole system and believe that this system has humanistic parameters which need to be nourished intellectually.

"A like Access" (Fig 6.1b) represent the non-linear reality of the current OA in science - its dependence on individuals, institutions and policies. This context may change and the visual language would also change.

"A like Archaeology" (Figure 6.1c) includes as abstract expressions some of the hallmarks of archaeology - layering, popularity of circle structures (pits, houses, fortresses, etc.), the black layers of burnt villages; the chess as one of popular ornamental motifs, as well as a symbol of the world, etc. This communicates the complex character of archaeology that may also mean a hierarchy of values, which is still not well revealed in the scholarly and popular literature. The truth is that many intelligent minds depart from archaeology since neither the governments nor the related subcultures can resolve the actual question of treasure-hunters and collectors. Archaeologists are placed in a difficult situation, since by increasing the values of material culture, they stimulate an increasing of treasure-hunting. The most curious case studies come from Bulgaria. Beyond Vasil Bozhkov and Dimitur Ivanov, in the last decades, and in the context of excavations of Thracian tombs work by Georgi Kitov, some treasure-hunters have become among the richest Bulgarians. There are also ar- 
chaeologists who have developed the psyche of treasure-hunters instead of being attached to the paradigm of preservation of cultural heritage. Accordingly, what archaeologists publish as OA is as important as how they look at culture, society and the material past. The way they accept the material past may have enormous impact on human culture as repeating circles.

"S like Science" (Fig 6.1d) is based on the solid view on science as structure. Science connects the world as a whole, and the role of the scientists is to make new discoveries and new structures to actualise the wholeness of the complex world (nature and humans).

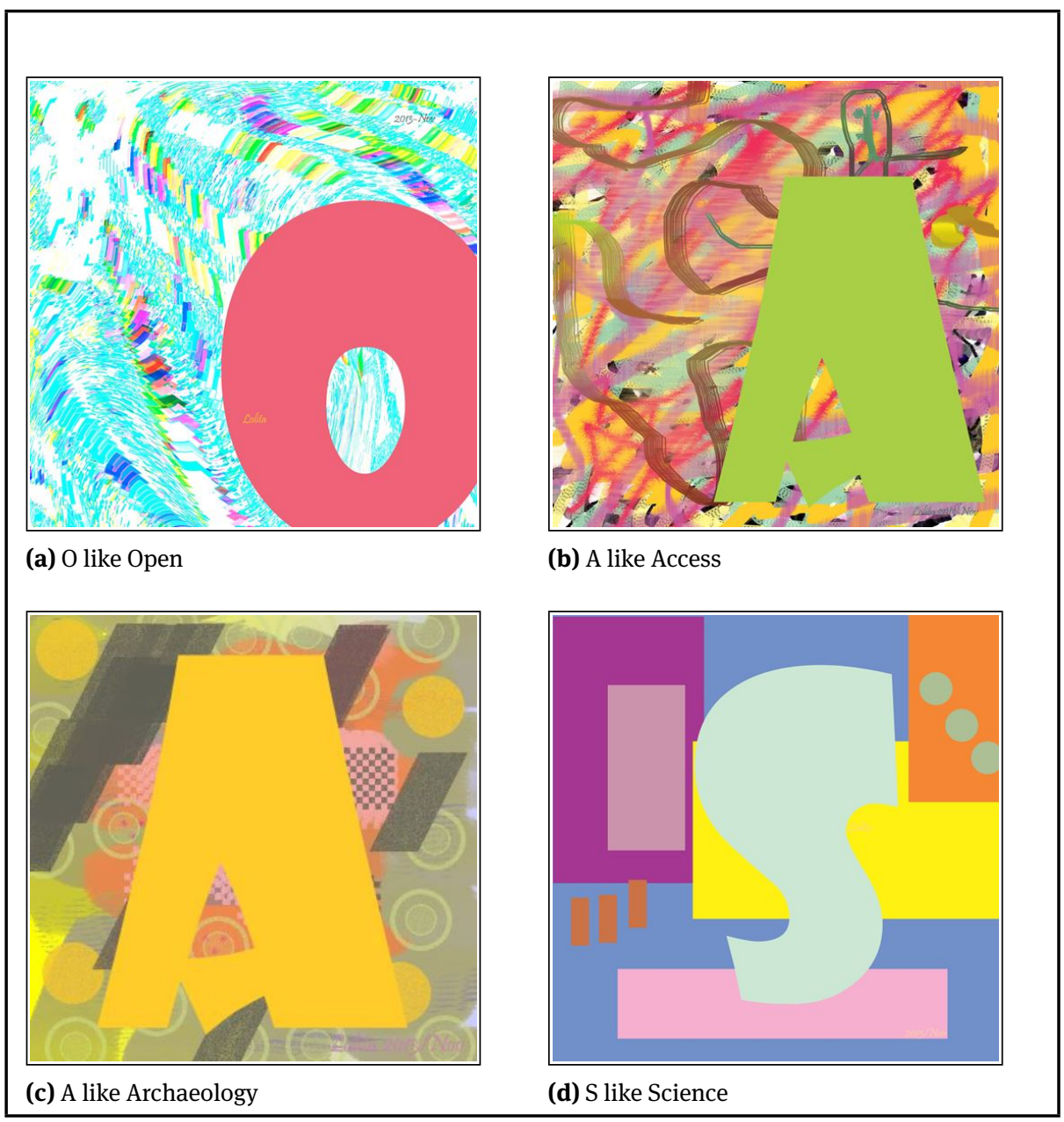

Figure 6.1: Four motifs demonstrate that the problem which combines open, access, archaeology and science 
The four motifs demonstrate that the problem which combines open, access, archaeology and science deals with different quality values, even the reflection towards possible conflicts because of this difference in the quality values.

\subsection{Open Access, Archaeology and Ethics}

OA archaeology has developed not only as a social practice, but also as a sub-branch of theoretical archaeology (Carver 2007; Lake 2012).

From a theoretical point of view, one of the key questions is: has archaeology become more influential in science and in society with development of OA and globalisation? Open Archaeology Access online has listed more than 200 journals which provide archaeological information from different parts of the world. This access theoretically should be able to change archaeological methodology and make archaeology much more influential in the field of science, especially in evolutionary research. The term evolution is not very clear, since the human culture knows both progress and devolution. Evolution may mean new quality changes in human society, which are usually non-invertible, but such changes may have a positive or negative value, then, change can be a progress or regress. To research evolution then means to prove a progression. Accordingly, in many cases evolution has not been used in the right way, since the so-called evolution could be a change, which has a negative impact on society.

Openness is expressed as open availability, or publicly available. It refers to:

1. specifications of a file format that are publicly available and accessible

2. the autonomy of a file format, which relies on several factors (self-contained document, structure, format, metadata information; (Park and Oh 2012, p. 48, see also Lake 2012; Beck and Neylon 2012).

The Directory of Open Access Journals (DOAJ) currently lists nearly 10,000 fully OA journals (Directory for Open Access Journals, n.d.).

A newly published OA article on "evolution of human family" (Smaldino et al., 2013) is a very good example how OA itself does not stimulate innovative research. While OA provides easy accessibility to the most recent literature, some scholars continue to believe that replicating methods based on very limited theoretical and methodological frameworks can be considered science and even be published by paid OA journals; that means additional expenses possibly applied to the institutions where the authors work. In many research disciplines scholars are locked in their own small debates, while the science of human civilisation needs a revolution in the understanding of science as a human interest, not as a field of human occupation alone. Smaldino et al. (2013) have occupied themselves in criticising the models of some of their colleagues, although their methodology of making models based on small samples looks itself, could be questioned. 
There are many examples in archaeology where the design of publications is a reproduction of local methodology which completely ignores OA publications that may change that methodology. Such publications keep archaeology at a lower level which is a crisis of context, since the traditionalists are very active - as in this case where the authors reportedly worked in an institute. In contrast, OA may stimulate high standards of reporting better serving the needs of 21st century science (see e.g. Sun et al. 2013).

OA itself does not mean democratisation of archaeology - it may create a more rigorous environment of censure, limiting access for people who have the power in the social practices and who in fact prevent the progress in archaeology.

As Olivieri recalls, “...most intellectual historians date the birth of modern science to the foundation of the Royal Society in Britain” (2006, p. 176). However, ethics and knowledge have become a problem since the earliest stage of human civilisation. The distribution of innovations, ceramic styles and exchange of objects were among the earliest contexts of the building of rules and the creation of norms of communication between individuals and communities.

One of the key issues of ethics is the fact that ethics as a cultural category has many ambiguous components, and is based often on fragmented behaviour. For instance, an author in science in fact can be a psychotronic terrorist who has been using science to masking antisocial behaviour. In the same way OA journals may in fact represent an attempt of a group of scholars to use science for non-ethical social practices (censure in publication, activity which in fact replace most actual for society critics, etc.). Global society is an integrated community. It is multicultural society with mixed view on traditions, science and ethics.

On the whole, the personalities of people have changed since they have been armed with the internet and after the end of Cold War (1989), the value of people today is first of all their personality. Negative (e.g. authoritarian or visible or invisible violent) personalities devalue their own cultural products. The Global Age (the period after 1989) is an Age of moral revolution. The existence of human civilisation depends on the results of this moral rebuilding of global society. OA is a powerful positive step in making society accessible, transparent and communicating based on valid actual data. However, OA has had a diverse response in archaeology, with doubt thrown upon the ethics of certain researchers (e.g.Bartman 2012; Kansa 2012). Copyright and peerreview is an issue of ethical debate. According to Harnad (2007), peer-to-peer access is far more important than direct public access and OA needs to be mandated for all research, by researchers' institutions and funders.

\subsection{Conclusions}

The following conclusions summarize the main points in this chapter:

1. Archaeology as a discipline is still at a stage of emerging OA discipline, since the 
open success publications are insufficient in compare of the traditionally published archaeological works.

2. OA theoretically would provide a stage of revolution in archaeology since having easy accessible publications online would stimulate research, as well as information from archaeology which may have high positive values of advance of culture and the relation of people to human culture. However, as in the motifs outlined above, there is a communication of different quality values which complicate the problem of faster integration of archaeology in the global OA community.

3. Development of OA in archaeology may stimulate the advance of the other sciences with direct or indirect links to archaeology. However, the research in the different archaeological fields as branches of complex social science in many cases is traditional, and archaeological publications often do not meet the criteria to be useful for research from other scientific branches.

4. Development of OA may increase the culture of archaeologists and invite in archaeology intellectuals with deep interest in culture.

5. Development of OA in archaeology may increase the numbers of authors who do not work in the field of archaeology but use archaeology for their research.

6. Advance in the OA of science of archaeology would stimulate increasing of value of archaeological publications and the value of archaeologists as people who make and not destroy and consume culture.

7. OA may increase the competition and corruption in archaeology since some may use OA journals to drawing a specific picture of national archaeologies serving political and ideological goals (especially in small countries like Bulgaria).

On the whole, archaeology is a field of social human activities, in which different people work, and OA is an opportunity to change of the types of personalities who chose archaeology as their field of human interest. OA increases the opportunity for critical approach, then, as authors will rely mostly on professionalism and not on power and positions. Many professors who use their power in a corruptive way will lose the main weapon of reproduction in archaeology - choosing specific people with multipersonalities with the only goal to reproduce their own heritage non-critically.

OA if it develops as a positive social practice, will probably make a revolution in ethics in archaeology and will make archaeology a stage of dominated positive values.

\subsection{The Future}

Some authors are afraid to predict the future of digital publishing (Arms, 2000, p. 263). However, others like Neylon state that the “... difference between the utopian and dystopian futures ... is public engagement in science. My suspicion is that if we can't bring interested members of the public into the process of research then we won't be looking at a happy future in terms of funding." (Neylon, 2013, p. 4). 
It is very easy to make analogies between genealogy and archaeology as disciplines. Both are integrated with society. However, while genealogy has been blooming on the internet, archaeology is one of the least represented disciplines although a considerable part relates to visual culture. Involving those interested with archaeological education in archaeological research - from the field to the theory - is not a utopia; it is a very beneficial and possible to realize this process. Such integration will increase the quality of personalities of archaeologists and will make sense of OA not as a field of academic competition, but a field of complex research of archaeology as a segment of complex science.

Expanding of the meaning of the OA archaeology together with enriching of the existed branches of OA (journals, e-books, metadata, "green" files, etc.) is a real step in making OA the dominant mean of archaeological publications and a way to integrate archaeology as a real essential segment of the complex science.

\section{Bibliography}

Arms, W. Y. (2000), Digital libraries, MIT press.

Bartman, E. (2012), 'From the president: Open access', Archaeology 65(3).

Beck, A. and Neylon, C. (2012), ‘A vision for open archaeology', World Archaeology 44(4), 479-497.

Björk, B.-C., Welling, P., Laakso, M., Majlender, P., Hedlund, T. and Gunason, G. (2010), ‘Open access to the scientific journal literature: situation 2009', PloS one 5(6), e11273.

Carver, M. (2007), 'Archaeology journals, academics and open access', European Journal of Archaeology 10(2-3), 135-148.

Directory for Open Access Journals (n.d.). URL: http://doaj.org/

Emmett, A., Stratton, J., Peterson, A. T., Church-Duran, J. and Haricombe, L. J. (2011), 'Toward open access: It takes a “village", Journal of Library Administration 51(5-6), 557-579.

Harnad, S. (2007), 'Ethics of open access to biomedical research: just a special case of ethics of open access to research', Philosophy, Ethics, and Humanities in Medicine 2(1), 31.

Kansa, E. (2012), 'Openness and archaeology's information ecosystem', World Archaeology 44(4), 498-520.

Kurata, K., Morioka, T., Yokoi, K. and Matsubayashi, M. (2013), 'Remarkable growth of open access in the biomedical field: analysis of PubMed articles from 2006 to 2010', PloS one 8(5), e60925.

Lake, M., ed. (2012), Open archaeology, Vol. 44, Taylor \& Francis.

Lenzer, J. (2008), 'Us congress and european research council insist on open access to research results', BMJ 336(7637), 176-177.

Macilwain, C. (2013), 'Is open access finally on the ascendancy? this may be the year for reality to catch up with rhetoric', BioScience 63(1), 7-11.

McCabe, M. J., Snyder, C. M. and Fagin, A. (2013), 'Open access versus traditional journal pricing: Using a simple "platform market” model to understand which will win (and which should)', The Journal of Academic Librarianship 39(1), 11-19.

Neylon, C. (2013), 'Architecting the future of research communication: building the models and analytics for an open access future', PLoS biology 11(10), 1-5.

Nikolova, L. (2013), ‘Open access archaeology and open science’, examiner.com. URL: http://www.examiner.com/article/open-access-archaeology-and-open-science 
Nwagwu, W. E. (2013), 'Open access initiatives in africa-structure, incentives and disincentives', The Journal of Academic Librarianship 39(1), 3-10.

Olivieri, R. (2006), 'Business, science, and the common good', Journal of library administration 44(3-4), 173-185.

Park, E. G. and Oh, S. (2012), 'Examining attributes of open standard file formats for long-term preservation and open access', Information Technology and Libraries 31(4), 46-67.

Smaldino, P. E., Newson, L., Schank, J. C. and Richerson, P. J. (2013), 'Simulating the evolution of the human family: cooperative breeding increases in harsh environments', PloS one 8(11), 1-12.

Suber, P. (2012), Open Access, MIT Press.

URL: http://cyber.law.harvard.edu/hoap/Open_Access_\%28the_book\%29

Sun, G. H., Aliu, O. and Hayward, R. A. (2013), 'Open-access electronic case report journals: the rationale for case report guidelines.', Journal of clinical epidemiology 66(10), 1065-1070. 